\title{
Retinal hemorrhages
}

National Diabetes Information Clearinghouse (NDIC)

\section{Definitions}

Blood vessels

Defined by National Diabetes Information Clearinghouse (NDIC)

Retina

Defined by National Diabetes Information Clearinghouse (NDIC)

Protein

Defined by National Diabetes Information Clearinghouse (NDIC)

Diabetic retinopathy

Defined by National Diabetes Information Clearinghouse (NDIC)

\section{Source}

National Diabetes Information Clearinghouse (U.S.). (2009). The diabetes dictionary. [Bethesda, Md.]: U.S. Dept. of Health and Human Services, National Institutes of Health, National Institute of Diabetes and Digestive and Kidney Diseases, National Diabetes Information Clearinghouse.

Bleeding blood vessels in the retina, which can cause protein deposits, or exudates, in the retina. Laser surgery is required to prevent blindness. Retinal hemorrhage is a common form of diabetic retinopathy. 